\title{
NOTE ON FOREIGN WORDS
}

With some modifications, the orthography developed by Chamberlain $(18956)$ has been employed in transcribing Okinawan speech, but use of the macron has been omitted and the vowel has been repeated to indicate length. His attempt at handling the glottal has been eschewed altogether without, I believe, any gross injustice to later attempts at replication. With the exception of proper nouns, Okinawan words have been italicized throughout. Japanese (and occasionally Chinese) terms, set off by single quotation marks, have been included where actual cognates or reasonable synonymity might bring greater clarity. Unless otherwise noted, Okinawan terms are rendered in the dialect of Naha, the largest population center. Each term has been defined at first appearance, and a glossary has been provided following the text. The Japanese and Okinawan practice of giving the surname first has been followed in the text. 